\title{
Educar para a "grande saúde" - vida e (trans) formação
}

Cleber Gibbon Ratto ${ }^{1}$

Simone Chaves Machado da Silva ${ }^{2}$

RATTO, C.G.; SILVA, S.C.M. Educating for "great health" - life and (trans) formation.

Interface - Comunic., Saude, Educ., v.15, n.36, p.177-85, jan./mar. 2011.

This essay resulted from the life experience and reflections of two healthcare professionals (a psychologist and a nurse) with daily involvement in professional training within higher education. It puts into the picture the power of encounters as (trans) formation processes, especially when education, language and health are the desire intermediation terms. It puts into question the encounters that vitalize or weaken the professional training process as a self-training experience of ethicalesthetic-political nature that goes beyond training technical and scientific skills and abilities. The text also aims to show the power of informality in constructing new knowledge, thereby allowing hybrid learning in which it is no longer certain for what time we are nurses, psychologists, teachers, philosophers or friends, which enables and from which comes a transdisciplinary attitude.

Keywords: Education. Health. Transdisciplinarity. Training.
Este ensaio resulta da experiência de vida e reflexão de dois profissionais da área da saúde - psicólogo e enfermeira implicados pelo cotidiano da formação profissional no ensino superior. Coloca em cena a potência dos encontros como processos (trans) formadores, sobretudo quando educação, linguagem e saúde constituem os termos de um agenciamento de desejo. Colocam-se em questão os encontros que vitalizam ou amortecem o processo da formação profissional como experiência autoformativa de caráter ético-estéticopolítico, para além da formação de competências e habilidades técnicocientíficas. O texto objetiva mostrar a potência da informalidade na construção de novos saberes, permitindo aprendizados mestiços, onde já não sabemos ao certo em que tempo somos enfermeiros, psicólogos, professores, filósofos ou amigos, o que permite e de onde provém uma atitude transdisciplinar.

Palavras-chave: Educação. Saúde. Transdisciplinaridade. Formação.

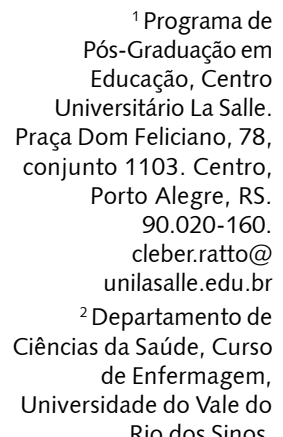

ós-Graduação em

Educação, Centro ( aça Dom Feliciano, 78, 1103 . Centro,
Porto Alegre, RS. 90.020-160. cleber.ratto@ unilasalle.edu.br Ciências da Saúde, Curso Universidade do Vale do Rio dos Sinos. 
A arte é o grande estimulante da vida.

Nietzsche (2006, p.18)

Este ensaio se dá numa zona de encontro de dois pesquisadores e suas multidões. Multidões que se revelam em "os outros", aqueles que nos habitam e que provocam cruzamentos singulares da fusão da pedagogia com a vida. Aprender, segundo Serres (1993), é a criação do terceiro, do mestiço, que assedia nossas palavras e línguas. Este trabalho, busca, na potência dos encontros dos "nossos outros", pensar os processos (trans)formadores, sobretudo onde educação, linguagem e saúde constituem os termos de um importante agenciamento. Colocam-se em questão os encontros que vitalizam ou amortecem o processo da formação profissional como experiência autoformativa de caráter ético-estético-político (Rolnik, 1993), para além da formação de competências e habilidades técnico-científicas.

Enfermeira e psicólogo. De um encontro nada informal nasce a potência de pensarmos a formação na área da saúde como algo que considere a suavidade da informalidade, daquilo que se dá e acontece no momento em que estamos vulneráveis ao outro e aos acontecimentos. Este texto quer apresentar a potência da informalidade na construção de novos saberes, permitindo aprendizados mestiços, onde já não sabemos ao certo em que tempo somos enfermeiros, psicólogos, professores, filósofos, amigos ou vizinhos. O que se pode garantir é que ele é o resultado de vários e alegres encontros, que nos precedem e nos ultrapassam.

\section{Educação}

Todo projeto de "formação" se pretende vencedor. As pedagogias são feitas para a vitória sobre a multiplicidade. Educar é organizar as forças vivas do mundo, submetendo-as à consciência, à unidade do "eu" e à linguagem. Invariavelmente, uma pedagogia pretende dar forma, inteligibilidade e comunicabilidade ao conjunto de forças implicadas na existência. Educar, pedagogizar ou formar, se preferirmos, é fazer existir no mundo da molaridade. É produzir um plano de organização.

A rigor, nenhum problema nesse intento. A própria função primária da linguagem, como veremos a seguir, é esse aquietamento do mundo na constituição de uma forma. Fazer o mundo passar pela linguagem e pela consciência é o que há de fundamental na experiência civilizada de sociabilidade humana. O projeto moderno de formação humana, no entanto, levou à sua máxima potência essa pretensão. E a educação é a grande máquina operadora dessa vontade.

A modernidade é definida, entre outras coisas, pelo advento da razão esclarecida, constituída, sistematicamente, em movimentos culturais, políticos e intelectuais desde o século XVI, em que o sujeito se pensa como o centro principal de referência de qualquer verdade sobre o que existe. Especialmente a partir daí, a razão pretendeu-se ordem e medida de todas as coisas e trabalhou pelo estabelecimento de uma forma hegemônica de constituição da verdade, assegurada pelos princípios da técnica.

A ciência moderna, diretamente dependente da duplicação empírico-racionalista do sujeito (Foucault, 2002), torna-se a instância privilegiada de produção das verdades, funcionando como a grande agência do logos humano, outrora encarnado exclusivamente na filosofia. Indicar a razão como marca predominante da modernidade, implica referir-se à sua impregnação pelo sonho da Aufklärung, do esclarecimento que permite melhor governar.

Referindo-se ao empirismo inglês de Francis Bacon e ao racionalismo do francês René Descartes, sistemas de pensamento que sustentarão o otimismo científico moderno, Giacóia Júnior (2005) corrobora a tese de que o grande fascínio do homem moderno pela razão implica diretamente uma forma de intervenção sobre o mundo, com o propósito de conhecê-lo e controlá-lo, na busca por felicidade e justiça. E nisso está o sonho de autonomia humana, para a qual a Educação deveria concorrer.

Tal como se atesta nessa inspiração dos pioneiros da moderna Aufklärung, um otimismo triunfalista está na base do credo científico desses pensadores: a razão, com base na ciência e na técnica, que dela decorre, pode enfrentar e resolver com sucesso os mais importantes 
problemas humanos, de modo a garantir o domínio sobre as forças da natureza, assim como realizar a justiça nas relações entre os homens. (Giacóia Júnior, 2005, p.102)

Sistematicamente, o mundo moderno atualizou a antiga noção grega da razão como essência diferencial do humano. Durante muito tempo, buscou-se exercitar a razão no sentido de se ampliarem as formas de entendimento de tudo o que há, fazendo com que ela não apenas se explique a si mesma como também dê conta de explicar aquilo que a ultrapassa. Como se tudo - mesmo o que esteja fora da razão, supostamente fora de seu alcance - terminasse por responder ao seu domínio. Quando sobreveio a ideia da emancipação, da razão iluminista insuflando o ideal emancipatório, a modernidade empurrou o sujeito para a necessidade de se emancipar pelo esclarecimento, pela ilustração, pelo estabelecimento de uma verdade e uma moral, ela também emancipatória. E a razão, crivo de tudo o que passa pelo pensamento, foi quem capitaneou esse ideal e criou as diretrizes para os projetos educacionais modernos (Pereira, Ratto, 2009).

A modernidade pretende uma "formação" que se entende como um direcionamento da alma e do espírito através da educação, não apenas para capacitar o homem técnica mas, também, moralmente. Trata-se de fazer do homem do conhecimento e da moral um agente na determinação da verdade.

A crise da modernidade resulta da constatação de que o mundo não é naturalmente racional. A razão é uma condição humana. E o mundo simplesmente acontece, ele não cessa de se arranjar, não para de acontecer. A razão acaba ficando em defasagem, um instante após o mundo ir se arranjando. $\mathrm{O}$ mundo vai acontecendo, as coisas vão sendo, e isso tudo que acontece e existe é como uma amostra da sua sustentabilidade, do jeito que as coisas são e conseguem ser, mesmo quando não cabem na razão. As coisas são o que elas podem ser. As coisas não são o que elas querem ou devem ser. Assim a razão, paradoxalmente, enquanto sonho e pesadelo da modernidade, realiza-se apenas na "loucura da linguagem", e, longe de ser um a priori do humano, constitui-se e impõe-se como decorrência de sua fragilidade.

Assim, qualquer pedagogia é também uma constante frustração. Porque uma pedagogia se pretende a priori vencedora, mas porque o mundo resiste à formação que ela pretende, sempre há uma decepção. A decepção de não conseguir exatamente o que se pretendia.

Mas talvez aí resida uma importante potência de toda pedagogia. A capacidade de acolher essa decepção. Uma espécie de reconhecimento da vulnerabilidade. Uma pedagogia aberta ao encontro do inesperado, aquilo que acontece fora do controle, que vibra no ineditismo de cada nova aproximação, cada novo apaixonamento. Talvez, inclusive, isso já não seja mais uma pedagogia. Pelo menos não a priori. A vulnerabilidade é bem mais uma condição, não propriamente consciente ou autônoma, mas uma disposição da própria vida para ser afetada, interferida.

A formação, propriamente, continuará ocorrendo, por certo. Não é possível pensar uma pedagogia que se pretenda a priori derrotada. É preciso querer vencer para poder jogar. A questão está no modo como se concebe a interferência, a afecção pelo imprevisto, por tudo aquilo que foge ao controle da consciência e da linguagem. Nisso reside a possibilidade de uma "grande saúde", como a concebe Nietzsche. Uma saúde que inclui a moléstia. Aliás, uma saúde que só se faz no jogo guerrilheiro da convalescença.

Uma (trans)formação pressupõe trabalhar com a processualidade da vitória e da saúde. Um jogo interminável de luta é aquilo que define vitória e saúde numa perspectiva mundana. Vitorioso e saudável é estar no jogo.

A possibilidade da vulnerabilidade é a educação para além da técnica e da moralidade, uma educação que perceba os acontecimentos do mundo, uma pedagogia que não resista às fragilidades e às moléstias.

Trata-se de resistir à captura de certas objetivações de sujeitos.

A captura a que estamos nos referindo é aquela operada pela temporalização moderna. $O$ emaranhado de disciplinamento e imposição moral que os processos educativos provocam nas pessoas e nos modos de estarmos no mundo. O tempo de confinamento da subjetividade e esquadrinhamento da consciência. Captura que impregna de impotência a subjetividade, provocando culpabilização e individualismo. Falamos de uma captura aliciadora que aliena as singularidades emergentes. O paradoxo 
estabelecido aqui é o de que a educação, que tem por vocação a transformação, entrega-se à subjetivação capitalística e mobiliza seus exércitos nessa direção.

\section{Linguagem}

A ideia do "Ser" pressupõe uma partição do mundo que acaba por criar um duplo, onde a verdade está escondida por detrás das aparências. Assim, o Ser jamais seria a própria aparência, porque esta sempre funcionaria como um encobrimento da verdade essencial das coisas.

\footnotetext{
É precisamente essa duplicação que é recusada por Nietzsche, cujo pensamento se desenrola em um único plano. [...] O que Nietzsche recusa ao negar o Ser não é, portanto uma instância ontológica, mas a hipótese de uma duplicação ontológica: a hipótese de que a realidade aparente seja a expressão de uma essência, de que o fluxo do devir seja a manifestação de um mundo do ser, que a existência sensível seja o desdobramento de uma instância suprassensível, que as construções perspectivas sejam a representação de um mundo constituído. (Rocha, 2003, p.44-5)
}

Nietzsche faz do mundo uma realidade sempre imanente, onde não há lugar para outro mundo que Ihe dote ou funde um sentido absoluto. Assim se instala o problema do conhecimento, que tradicionalmente atende à vontade de consciência a respeito do mundo.

Ele assume que o "erro hereditário" de todos os filósofos é não reconhecer que também a faculdade de conhecer tem um curso histórico ou, mais propriamente ainda, uma pré-história biológica (Safranski, 2005).

É do ponto de vista genealógico que Nietzsche destituirá a consciência e a linguagem de seu estatuto privilegiado de funções "essenciais".
Pois, para dizê-lo mais uma vez: o homem, como toda criatura viva, pensa continuamente, mas não sabe disso; o pensamento que se torna consciente é apenas a mínima parte dele, e nós dizemos: a parte mais superficial, a parte pior: - pois somente esse pensamento consciente ocorre em palavras, isto é, em signos de comunicação; com o que se revela a origem da própria consciência. (Nietzsche, 2002, p.249)

Assim, a linguagem e a consciência respondem, já em seu nascedouro, àquilo que a estrutura racional nascida com a filosofia socrático-platônica traz como fundamento: uma necessidade de duração como modo de aquietar a multiplicidade caótica e movente do mundo.

As "linguagens são instrumentos de narcisismo de grupo; se tocam para afinar e voltar a afinar os instrumentistas" (Sloterdijk, 2005, p.13, tradução dos autores).

Os homens dispõem de linguagem para falar de suas próprias vantagens, entre elas - e não é a menos importante - dessa insuperável vantagem que é poder falar de suas próprias vantagens na sua própria linguagem. E é, sobretudo, no individualismo moderno e no esteticismo contemporâneo, que essa pretensão de vantagem ganha uma força cada vez maior.

Com isso, Nietzsche aparece como a desconfortável provocação de nossa crença. O que entra em questão com a crítica nietzscheana é o modo como esse narcisismo primário da linguagem, constitutivo da humanidade, é reencenado na modernidade com a forma de elogio da (cons)ciência que faz do homem um soberano, capaz de "formar" e "autoformar-se".

O nascimento do homem com consciência epistemológica, simultaneamente condição e objeto do conhecimento, faz com que a linguagem assuma uma função ainda mais drástica: dizer a verdade do "eu". A linguagem comete uma loucura, como sugere Nietzsche. "Bela loucura a da linguagem: graças a ela o homem baila sobre todas as coisas" (Nietzsche, 2000, p.259) E agora, modernamente, pretende bailar sobre ele mesmo. Isso só pode se dar no solo positivo da episteme moderna. O homem vira medida do mundo. E a experiência mundana vai sendo ofuscada pela supremacia da linguagem fazedora de consciência. 
O que manifesta, em todo caso, o específico das ciências humanas, vê-se bem que não é esse objeto privilegiado e singularmente nebuloso, que é o homem. Pela simples razão de que não é o homem que as constitui e lhes oferece um domínio específico; mas, sim, é a disposição geral da episteme que lhes dá lugar, as requer e as instaura - permitindo-lhes, assim, constituir o homem como seu objeto. Dir-se-á, pois, que há "ciência humana" não onde quer que o homem esteja em questão, mas onde quer que se analisem, na dimensão própria do inconsciente, normas, regras, conjuntos significantes que desvelem, à consciência, as condições de suas formas e de seus conteúdos. (Foucault, 2002, p.504)

E não se trata do "inconsciente" na forma que convencionalmente lhe atribuem as psicanálises. Inconsciente aqui seria "justamente essa região que não se expressa em palavras, o domínio que escapa à linguagem. Não é, pois, por acaso, que não tratamos do inconsciente em Nietzsche; além de não existir aí enquanto conceito, o que se poderia chamar eventualmente de inconsciente remete, de imediato, ao indizível" (Marton, 2001, p.181). Inconscientes seriam todas as forças vivas do mundo que não cabem na linguagem.

A linguagem, então, é tomada aqui como a expressão sempre reencenada de um narcisismo primário. Uma vontade de duração, de ordem, de aquietamento identitário.

Desconsidera-se que a própria linguagem é um agenciamento coletivo de enunciação (Deleuze, Parnet, 1998), em última análise, composta por forças maquínicas do desejo que lhe precedem.

Assim, a linguagem adoece o mundo, porque amortece sua potência. E a "grande saúde" em Nietzsche aparece como o "fora" da linguagem. Essa vulnerabilidade àquilo que interfere na consciência, a razão, o "eu", potencializando os encontros, as contaminações, as mestiçagens. A assepsia da linguagem adoece a vida, ao passo que a "mistura" mundana favorece sua celebração.

A linguagem, como agenciamento coletivo, é produtora de subjetividades, determinando e legitimando as estruturas da sociedade, o modo como estamos ou devemos estar nela inseridos. No campo da saúde não é diferente. A linguagem cria e determina subjetividades e esta predeterminação bloqueia, na grande maioria das vezes, o que mais faz sentido em saúde: o cuidado, a proteção e a recuperação da vida.

\section{Saúde}

O problema da saúde percorre as preocupações de Nietzsche desde sempre. A pergunta de fundo, pela possibilidade de uma experiência vitalizante, próxima do inaudito do mundo, faz-se ao longo de toda a obra.

Nietzsche se intitula o primeiro grande psicólogo da Europa. "Que em meus escritos fala um psicólogo sem igual é, talvez, a primeira constatação a que chega um bom leitor - um leitor como eu o mereço, que me leia como os bons filólogos de outrora liam o seu Horácio" (Nietzsche, 1995, p.58).

Trata-se da "grande psicologia", aquela capaz de cumprir seu programa genealógico.

Ela funciona como um operador estratégico em sua genealogia da moral, em suas análises dos fenômenos religiosos, em sua apreciação das grandes personalidades históricas antigas e modernas, em sua crítica da ciência, da arte, da educação e da política, enfim, em sua inteira tarefa de 'médico e sintomatologista da cultura'. (Giacóia Júnior, 2001, p.10)

A crítica do psicólogo Nietzsche não incide apenas sobre o primado da consciência em detrimento das forças naturais, mas também sobre a unidade do "eu", base de todas as políticas educacionais e sanitárias modernas. A desconstrução do primado da consciência não produz efeitos apenas no campo da teoria do conhecimento ou na crítica da religião e da metafísica. Destituir a consciência de seu lugar privilegiado, como instância soberana de conhecimento do mundo, leva necessariamente à fragilização dos limites da individualidade dados pela identidade do "eu".

O "eu penso" e o "eu quero" são destituídos de sua onipotência e passam a existir na condição de efeitos, e não mais de agentes. $\bigcirc$ "eu" então funciona como uma síntese conceitual que permite, 
através da consciência, encobrir relações de força sempre pré-pessoais. O sujeito surge como uma ficção de unidade e coerência que somente a consciência e a linguagem, com finalidades comunicativas, conseguem organizar. "Algo pensa, mas que esse 'algo' seja justamente o antigo e célebre 'eu' é, dito com indulgência, somente uma suposição, uma asserção, mas nunca uma 'certeza imediata'" (Nietzsche, 2003, p.23).

Para Nietzsche (2003, p.25), "nosso corpo nada mais é do que um edifício coletivo de várias almas". E alma aqui designa o conjunto das forças e organismos microscópicos que compõe o corpo, em permanente disputa e tensão. $\mathrm{O}$ "eu", assim, funciona como um modo de estabilizar a multiplicidade e possibilitar, como uma ficção reguladora, o próprio conhecimento e comunicação do mundo.

Desse modo, a pretensão de autoconstituição pela linguagem, de autorreferência, de consciência de si, é o produto mais caro dos ideais emancipatórios do homem moderno.

O que importa aqui são os efeitos disso sobre a vida social, na medida em que essa pretensão moderna de autorreferência é a própria matriz de todas as nossas pedagogias. A modernidade é, antes de tudo, uma ética particular, na medida em que não apenas demarca um período histórico, senão que implica a formulação de um projeto de existência que nos "faz viver" dentro de certos parâmetros de verdade e normalidade. E é da linguagem, com sua bela loucura, que dependem todas as políticas de identidade que modulam os modos de vida.

Seja encarnada no pensamento mítico, nas pretensões da teologia, na soberania da ilustração, com a magia, com Deus ou com o homem, a vontade de ser pretende estabilizar o mundo dando-lhe ordem e viabilidade. Com isso, esqueceu-se que a linguagem é aparentada com a loucura do ser. Como uma tesoura, a linguagem parte o mundo e, duplicando-o, funda um além-mundo de onde os sentidos emanariam. Cria-se, com isso, um horizonte perdido, uma vida que estaria para além da própria vida, mais verdadeira, mais bela, melhor. Assim, o melhor do mundo passa a ser pelo que lhe falta, aquele mundo perdido que a linguagem e a cultura tentam perseguir, o mundo ideal.

Então, amar o que falta é a própria lei da linguagem. Amar aquilo que persegue sem nunca encontrar, a verdade, o ideal, o absoluto. Essa é a matriz de uma espécie de doença denunciada por Nietzsche, não apenas na tradição do pensamento científico moderno ou da cristandade, mas na própria raiz disso tudo, a pretensão humana de não ser o próprio mundo. E é dessa doença que se nutre a modernidade. A doença que advém do excesso de si e da falta de mundo. "O grande fastio que sinto do homem - isto penetrara em minha goela e me sufocava; e aquilo que proclamava o adivinho: 'Tudo é igual, nada vale a pena, o saber nos sufoca" (Nietzsche, 2000, p.261).

Mas permanece em Nietzsche a problemática tensão entre saúde e doença. Talvez não possamos prescindir da doença e em toda saúde também haja um pouco de enfermidade.

Enfim, permaneceria aberta a grande questão de saber se podemos prescindir da doença, até para o desenvolvimento de nossa virtude, e se a nossa avidez de conhecimento e autoconhecimento não necessitaria tanto da alma doente quanto da sadia; em suma, se a exclusiva vontade de saúde não seria um preconceito, uma covardia e talvez um quê de refinado barbarismo e retrocesso. (Nietzsche, 2002, p.120)

Curar-se dessa doença e conquistar uma grande saúde, no entanto, não se dá de um só golpe. Há toda uma convalescença necessária. Uma convalescença de quem está se curando da doença do ser. Porque também há uma enfermidade em toda redenção. As ciências humanas, de um modo geral, e a educação, em particular, são modernamente as figuras mais caras dessa vontade de ser e de verdade. A educação, em especial, responde pelo grande projeto de produzir o sujeito moral e deveria fazê-lo pela crença absoluta na identidade entre felicidade, moral e sabedoria. "De fato, como poderíamos tornar os homens felizes, se não os tornarmos morais e sábios?" (Kant, 1996, p.28).

É em Zaratustra que reaparece, de modo exemplar, a problemática relação entre saúde e doença, conhecimento e insondabilidade, mundo e "si mesmo". A saúde, passados sete dias de "conhecimento" e "criação" (figura emblemática da tradição filosófica e teológica ocidentais), é dar as costas à caverna para reencontrar o mundo. É dos animais que vem a sedução. 


\begin{abstract}
Sai desta caverna; o mundo está à tua espera como um jardim. Brinca o vento com intensos perfumes, que te procuram; e todos os córregos gostariam de seguir os teus passos. Por ti, que ficaste sozinho sete dias, anseiam todas as coisas. - Sai desta caverna! Todas as coisas querem ser teus médicos! (Nietzsche, 2000, p.259)
\end{abstract}

Zaratustra sabe que o remédio é cantar. Porque cantar talvez seja o modo mais eficaz de afrouxar a linguagem de sua pretensão de Verdade. Contudo, não se pode fazer do cantar uma modinha de realejo. "Que eu deva voltar a cantar - este consolo e esta cura inventei para mim; também disso quereis fazer logo modinha de realejo?" (Nietzsche, 2000, p.262) Zaratustra indica uma necessária convalescença.

Não se trata de anunciar entusiasticamente, na educação, o fim da modernidade, do homem, da verdade, das pedagogias vencedoras e de tudo o que, afinal de contas, é a própria condição de existência do homem que nos tornamos.

Trata-se, isto sim, de favorecer os encontros. "Acreditar no mundo é o que mais nos falta; nós perdemos completamente o mundo, nos desapossaram dele. Acreditar no mundo significa principalmente suscitar acontecimentos, mesmo pequenos, que escapem ao controle" (Deleuze, 1992, p.216).

A convalescença requer uma espécie de silêncio. O silêncio do apaixonamento, dos encontros intensivos, que sempre se dão num lugar além ou aquém da linguagem.

\begin{abstract}
Um passo adiante na convalescença: e o espírito livre se aproxima novamente à vida, lentamente, sem dúvida, e relutante, seu tanto desconfiado. Admira-se e fica em silêncio [...]. E, falando seriamente: é uma cura radical para todo pessimismo [...] ficar doente à maneira desses espíritos livres, permanecer doente por um bom período e depois, durante mais tempo, durante muito tempo tornar-se sadio, quero dizer, 'mais sadio'. Há sabedoria nisso, sabedoria de vida, em receitar para si mesmo a saúde em pequenas doses e muito lentamente". (Nietzsche, 2005, p.11)
\end{abstract}

Uma educação para a grande saúde é uma pedagogia da vulnerabilidade que rompe e se abre para o aprendizado de si, para o aprendizado que foge ao controle, que aceita a decepção e a mestiçagem como modo de existir.

Concebemos que o processo educativo, em geral, é um agente nesta captura da singularidade, neste aniquilamento da potência, que pode transformar a prática do trabalho de enfermeiros e psicólogos num ato repetitivo e entristecedor. Pensar num trabalho serializado significa dizer que o mundo do trabalho em saúde passa a ser um fardo para muitos, pois é o lugar da marginalização. É o lugar onde a técnica tem mais valor do que qualquer outra coisa, um lugar onde a criação não é legitimada, onde a contabilidade do tempo vale mais que o cuidado. O trabalho em saúde apesar de ser um trabalho vivo é um trabalho onde a expansão da vida é enfraquecida ou anulada.

\title{
Entre macro e micropolíticas
}

Jogar no exercício filosófico do pensamento - o que equivale a dar margem expressiva para os encontros que vivemos - nos permitiu conceber que todas as macropolíticas institucionais são potentes exatamente quando comportam vacâncias, falências ou vazios. Sejam as Diretrizes Curriculares Nacionais com suas disposições generalistas, sejam os Princípios do SUS, com sua defesa da integralidade, as macropolíticas só se fazem potentes ao abrirem espaço, ao darem margem para o imprevisto e o impensado dos encontros. Trata-se, antes de tudo, de uma micropolítica da vulnerabilidade. Uma micropolítica que favoreça a Grande Saúde, como a concebe Nietzsche. Saúde operada como estado de tensão, de jogo, de luta e de abertura ao outro. Não se trata de harmonia nem de estabilidade, mas de vulnerabilidade aos encontros de todo gênero. 
A potência de um programa ou de uma ação, para além de sua pretensão de vitória e sucesso, está dada por sua capacidade potencial de ser interferida. Trata-se de uma economia onde a força não está dada pelo que se "é", mas pelo que se pode vir-a-ser nos encontros que acontecem.

As mudanças têm acontecido em muitos lugares e, na educação ou na saúde, isso é muito evidente. Resta saber se essas mudanças já estão incorporadas, se já pertencem ao corpo de quem as promove. Identificarmos em que plano essas mudanças se dão é a grande dificuldade desse processo de (trans)formação quando pensamos na grande saúde.

Mudamos a forma de os cursos acontecerem dando margem para a vulnerabilidade, reformulamos suas bases conceituais, mudamos a lei, mas será que tais diferenças tocam efetivamente nossos corpos?

Esta reflexão é extremamente importante porque, se estamos falando, até o momento, das necessidades de mudança nos processos de aprendizagem, precisamos criar escuta das muitas vozes que compõem a paisagem contemporânea da saúde e da educação. De nada adianta rompermos com os processos moralizadores e objetivantes da educação se não conseguirmos perceber o que diz o aluno-trabalhador de nossos bancos universitários. A escuta aqui significa reconhecer que falamos de corpos (humanos, conceituais, técnicos) compostos na trama dos afetos.

Falamos de gente, de cidadania, de configuração de mundo, de potencialidade de mudança, de efetivação do Sistema Único de Saúde e da implementação de uma micropolítica do cuidado, onde a sensibilidade, o desejo e o afeto são indispensáveis no cotidiano do fazer saúde e educação.

Pensar no processo educativo como uma oficina de tempo é entender o tempo não como fluxo linear/educação vertical que nos atualiza, mas tempo como emaranhado de possibilidades - educação como rede rizomática, sem início e sem centro, rede de fluxos, cruzamentos de linhas de tempo, que nos remete aos mais incríveis devires, ao mundo dos possíveis, da invenção. Este pressuposto de invenção pode ser o caminho educativo utilizado para as (trans)formações necessárias em várias áreas e momentos da vida, sobretudo quando entendemos saúde como sendo a potencialidade máxima da vida.

Assim, este texto é o rastro dos encontros de nossas multidões, compostas por histórias vividas, contadas e testemunhadas nos espaços intersubjetivos de formação, onde nos pretendemos "(trans)formadores" de modos de existir, na profissão, no pensamento e na vida.

\section{Colaboradores}

Os autores trabalharam juntos em todas as etapas de produção do manuscrito.

\section{Referências}

DELEUZE, G. Conversações. Rio de Janeiro: Ed. 34, 1992.

DELEUZE, G.; PARNET, C. Diálogos. São Paulo: Escuta, 1998.

FOUCAULT, M. As palavras e as coisas. 8.ed. São Paulo: Martins Fontes, 2002. (Coleção Tópicos).

GIACOIA JUNIOR, O. Sonhos e pesadelos da razão esclarecida: Nietzsche e a modernidade. Passo Fundo: UPF, 2005.

Nietzsche como psicólogo. São Leopoldo: Ed. Unisinos, 2001. 
KANT, I. Sobre a pedagogia. Trad. Francisco Cock Fontanella. Piracicaba: Unimep, 1996.

MARTON, S. Extravagâncias: ensaios sobre a filosofia de Nietzsche. 2.ed. São Paulo: Discurso Editorial/Ed. Unijuí, 2001.

NIETZSCHE, F. Crepúsculo dos ídolos. São Paulo: Companhia das Letras, 2006.

. Humano, demasiado humano. São Paulo: Companhia das Letras, 2005.

. Além e do bem e do mal. 2.ed. São Paulo: Cia. das Letras, 2003.

A gaia ciência. São Paulo: Cia. das Letras, 2002.

Assim falou Zaratustra. 11.ed. Trad. Mário da Silva. Rio de Janeiro: Civilização Brasileira, 2000.

Ecce Homo. São Paulo: Cia. das Letras, 1995.

PEREIRA, M.V.; RATTO, C.G. Virtude é coisa que se ensina? O lugar do cuidado na formação. In: CAMARGO, A.M.F.; SOUZA, R.M.; MARIGUELA, M. (Orgs.). Que escola é essa? Anacronismos, resistências e subjetividades. Campinas: Alínea, 2009. p.59-74.

ROCHA, S.P.V. Os abismos da suspeita: Nietzsche e o perspectivismo. Rio de Janeiro: Relume Dumará, 2003.

ROLNIK, S. Pensamento, corpo e devir: uma perspectiva ético/estético/política no trabalho acadêmico. Cad. Subjetividade, v.1, n.2, p.241-52, 1993.

SAFRANSKI, R. Nietzsche: biografia de uma tragédia. Trad. Lya Luft. São Paulo: Geração Editorial, 2005.

SERRES, M. O terceiro instruído. Trad. Serafim Ferreira. Lisboa: Instituto Piaget, 1993.

SLOTERDIJK, P. Sobre la mejora de la buena nueva: el quinto "evangelio" según Nietzsche. Trad. Gérman Cano. Barcelona: Ediciones Siruela, 2005.

RATTO, C.G.; SILVA, S.C.M. Educar para la "gran salud" - vida y (trans) formación. Interface - Comunic., Saude, Educ., v.15, n.36, p.177-85, jan./mar. 2011.

Este ensayo resulta de la experiencia de vida y reflexión de dos profesionales del área de la salud - psicólogo y enfermera - implicados en el cotidiano de la formación profesional en la enseñanza superior. Coloca en escena la potencia de los encuentros como procesos (trans)formadores; sobre todo cuando educación, leguaje y salud constituyen los términos de un agenciamiento de deseo. Se plantean los encuentros que vitalizan o amortecen el proceso de la formación profesional como experiencia auto-formativa de carácter ético-estético-político. El texto quiere evidenciar la potencia de la informalidad en la construcción de nuevos saberes, permitiendo aprendizajes mestizos en los que no sabemos bien en qué tiempo somos enfermeros, psicólogos, profesores o amigos ni lo que permite y de donde proviene una actitud transdisciplinaria.

Palabras clave: Educación. Salud. Trans-disciplinaridad. Formación. 